\title{
號二十六百三第誌雜會究研事醫堂天順 入-
}

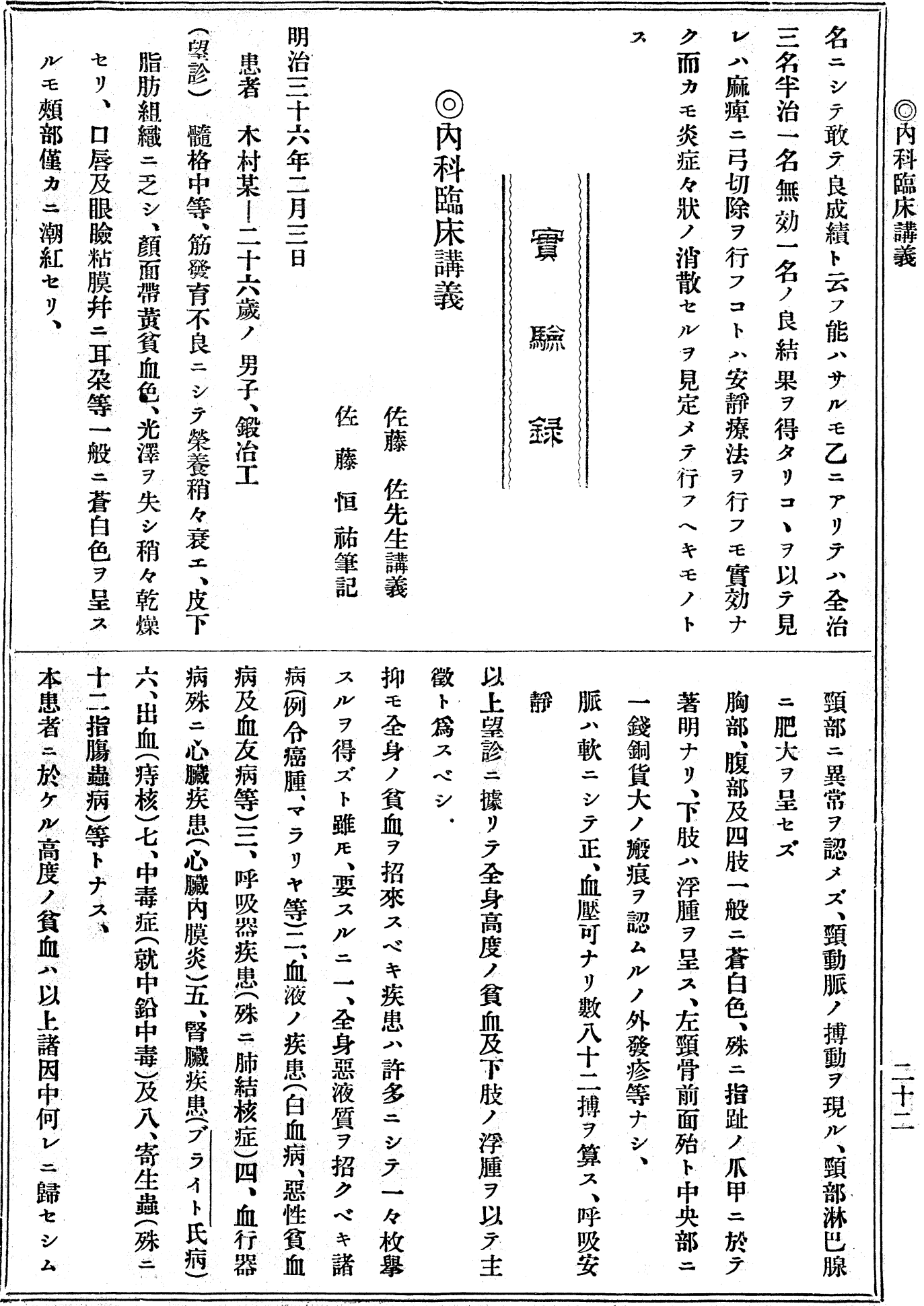




\section{九二D錄驗實誌雜會究研事醫堂天順}

克何 $==$ = 經 ナ タ茲べザ關毒 た

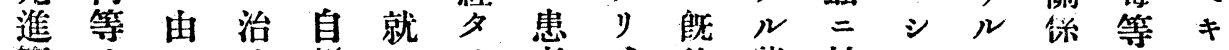

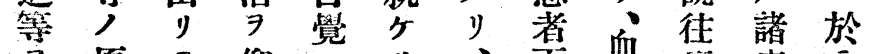

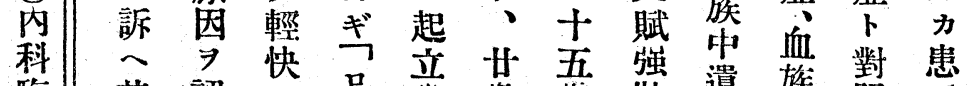

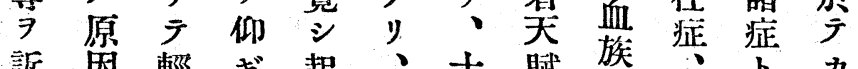

臨 某認二口步歲葴寢遺族照急

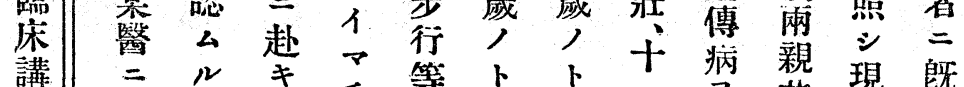

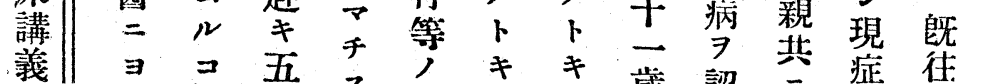

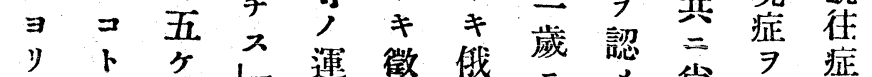

テナ月 ト 運 徵 俄

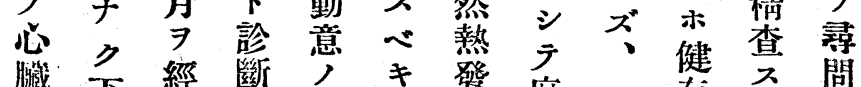

病 下 經 聯如原發麻存

肢全

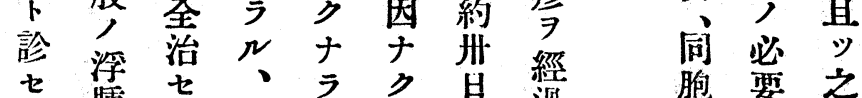

ラ腫り五ザシ, 過鸷要之

レ呼、千ルテ經 方

二吸甘旦 $尹$ 腰過種何

邀促三餘以部

間 迫葴, $\bar{F}$ 以數

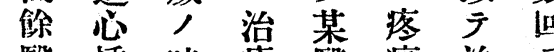

醫 悸 時 療 醫 痛 治 $\ni$

モ 由

健得

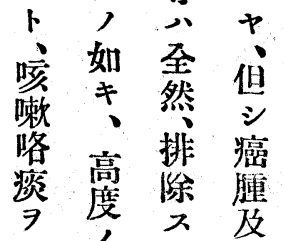

缺畕永

ス 血 得核

比 心期

カ 比

如 テ 何 惡

キ榮 何 液

等養ナ質

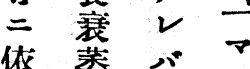

挔委患亏

テ甚著思

知夕, 只

沙年

）力踰 鉛

得 ラノ中

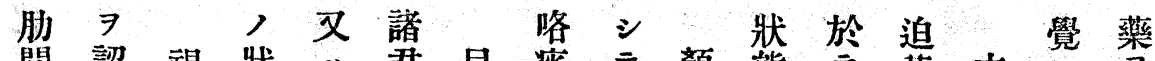

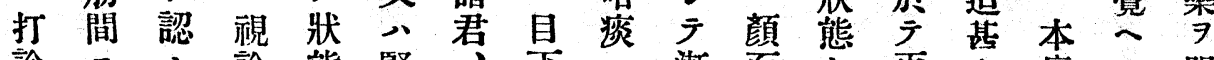

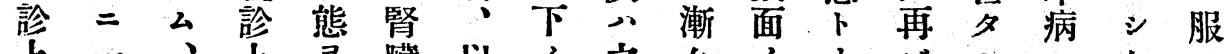

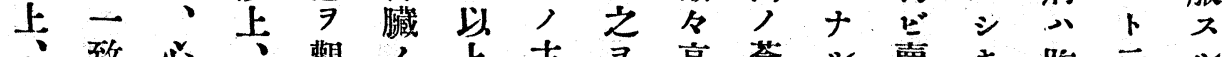

心致怘覗

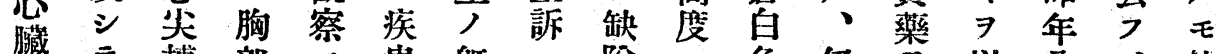

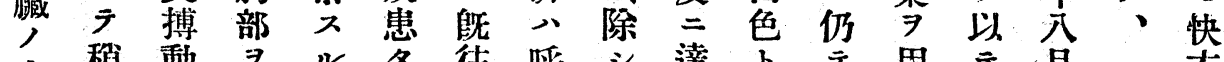

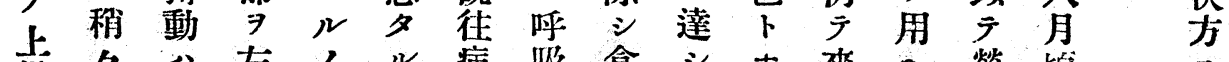

㕝々八左人病吸食

䒔擴乳右必 $习$ 歷促機

第張線比要疑卜迫害目 シ治 ガ

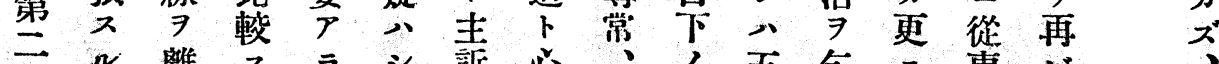

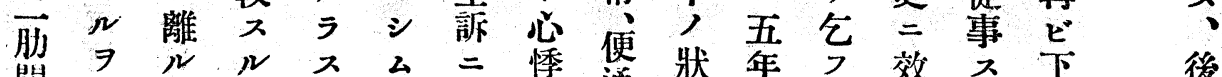

間見約二ス台徵兌通奬前 $、$ 效

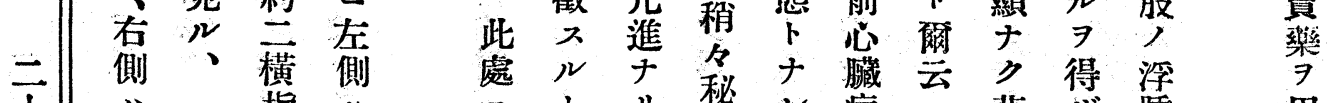

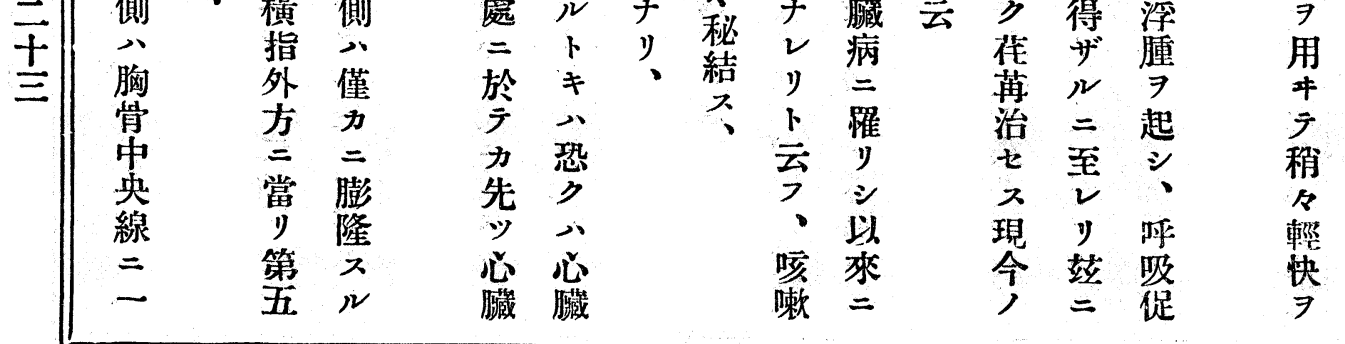


號二十六百三第誌雜會究研事醫堂天順 ○二-

\begin{tabular}{|c|c|c|c|c|c|c|c|c|c|c|c|c|c|c|c|c|}
\hline 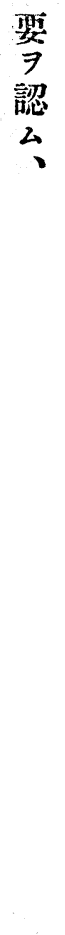 & 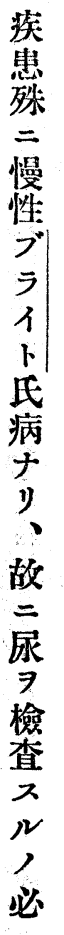 & 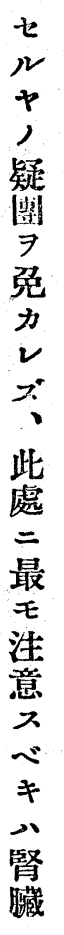 & 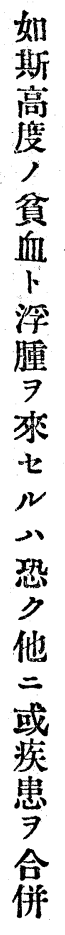 & 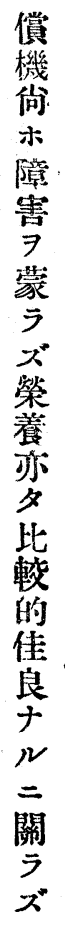 & 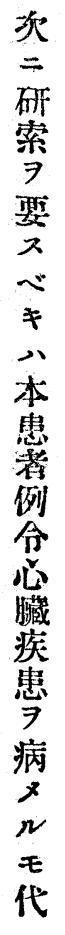 & $\begin{array}{l}\text { 屢 } \\
\text { \& } \\
\text { ナ } \\
\text { J }\end{array}$ & 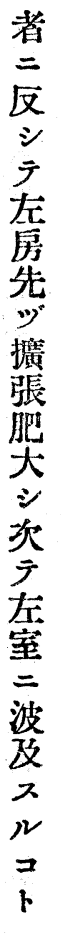 & 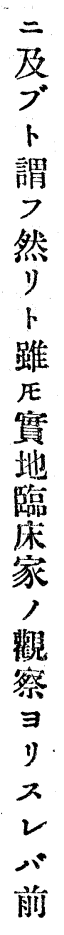 & 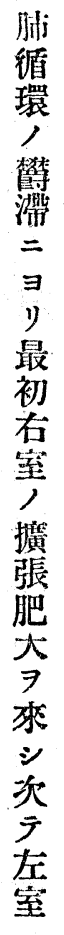 & 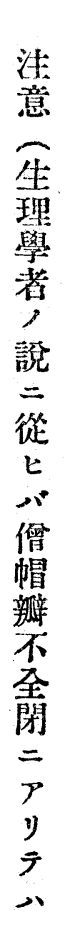 & 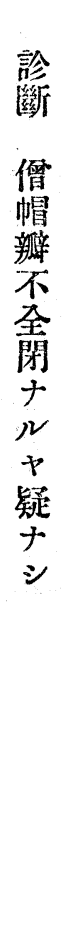 & $\begin{array}{l}\text { 以 } \\
\text { 上 } \\
\text { 理 } \\
\text { 學 } \\
\text { 的 } \\
\text { 檢 } \\
\text { 㹉 } \\
\text { 号 } \\
\text { F }\end{array}$ & 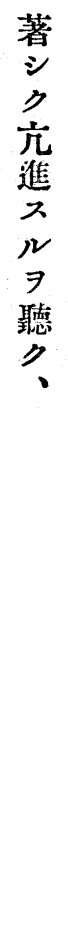 & 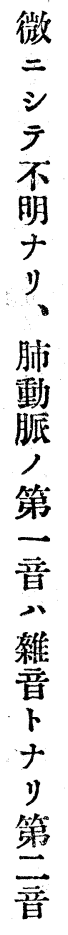 & 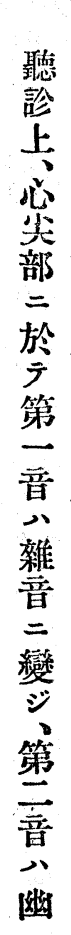 & 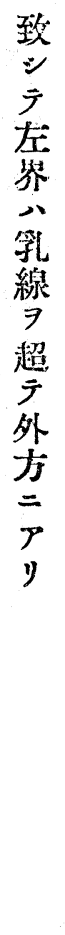 \\
\hline 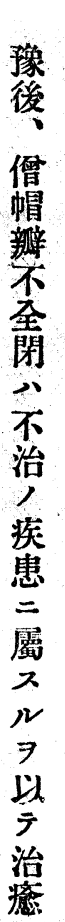 & 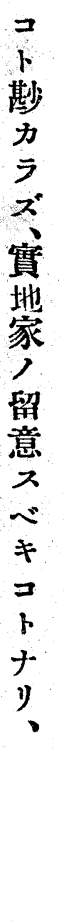 & 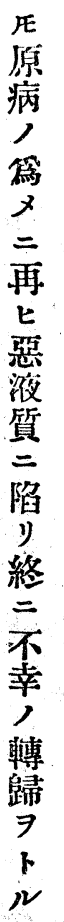 & 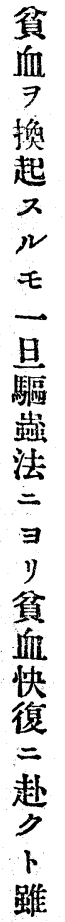 & 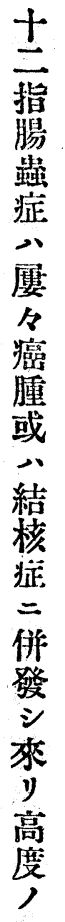 & 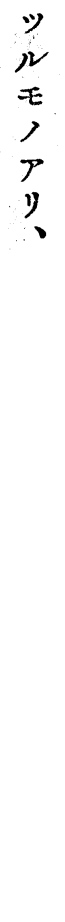 & 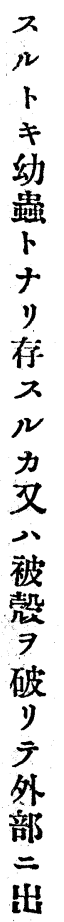 & 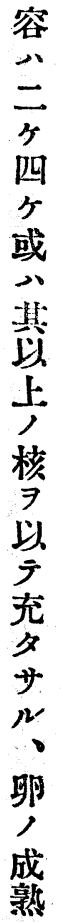 & 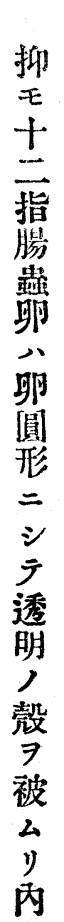 & 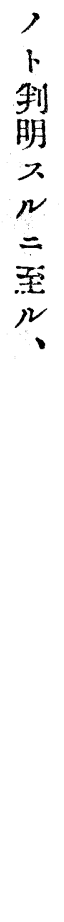 & 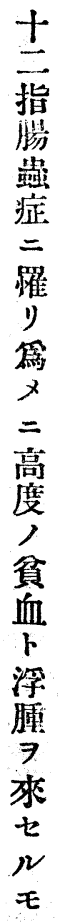 & 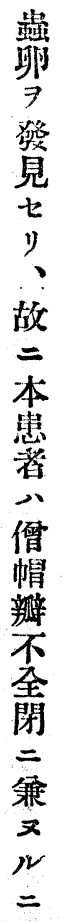 & 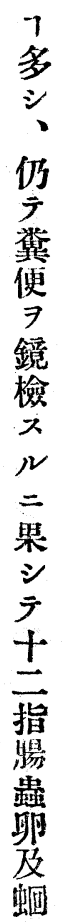 & 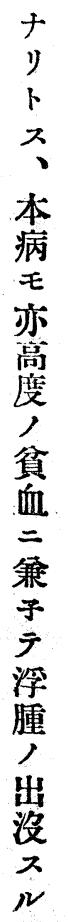 & 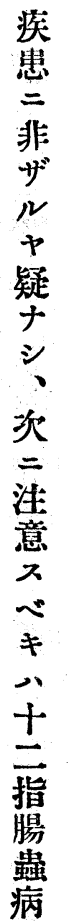 & 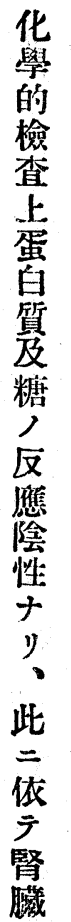 & 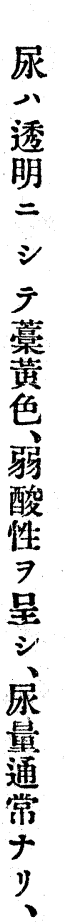 \\
\hline
\end{tabular}


二二一錄驗實誌雜會究研事醫堂天順

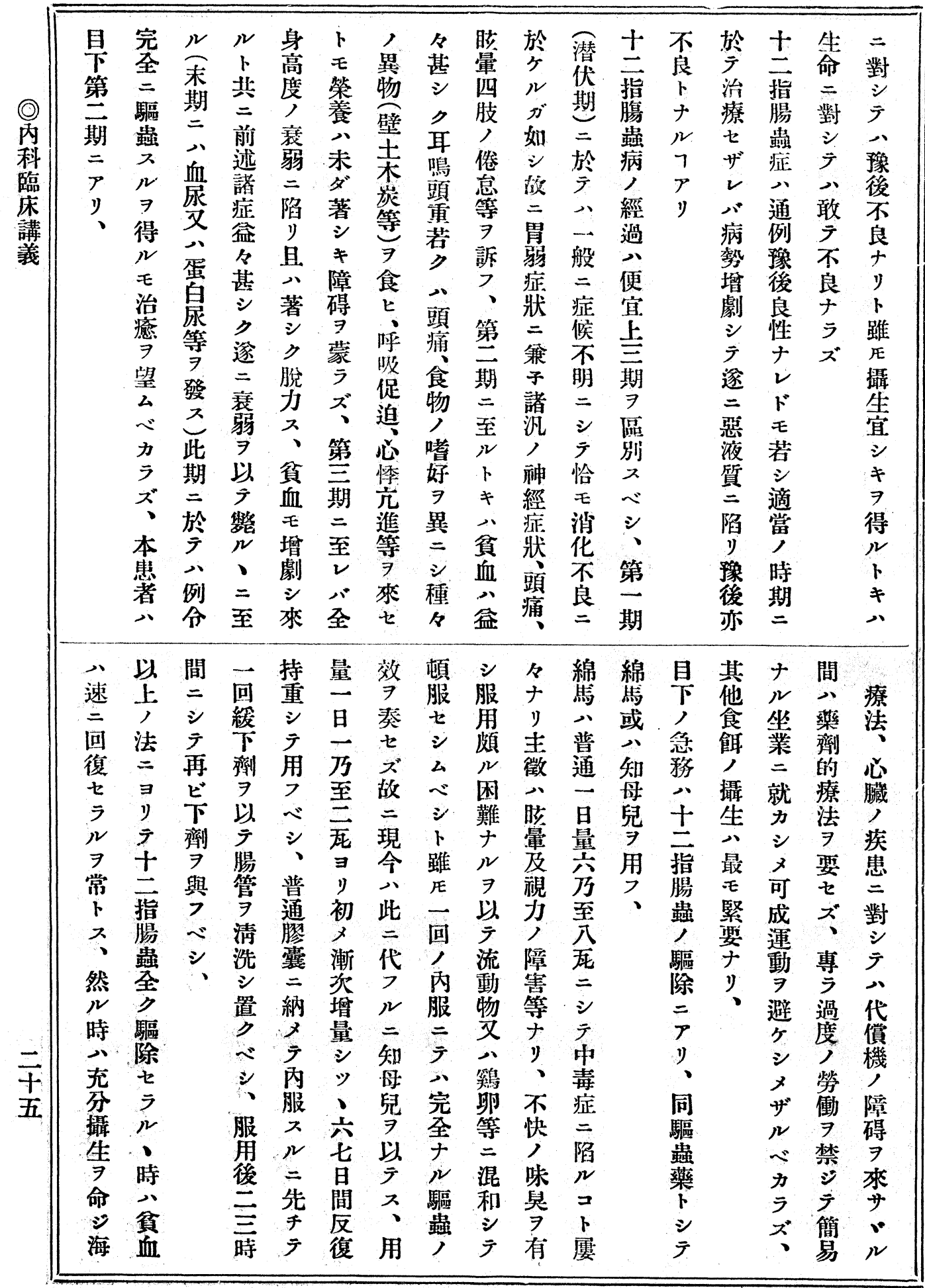


號二十六百三第誌襍會究研事醫堂天順 二二-

\begin{tabular}{|c|c|c|c|c|c|c|c|c|c|c|c|c|c|c|c|c|}
\hline 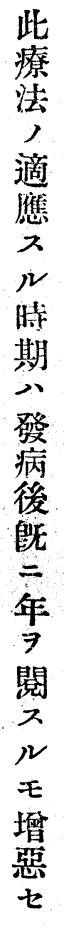 & 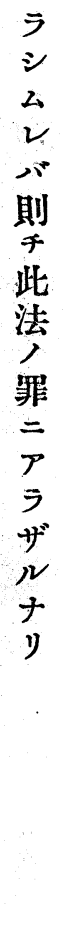 & 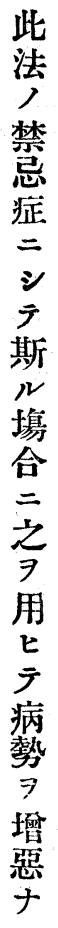 & 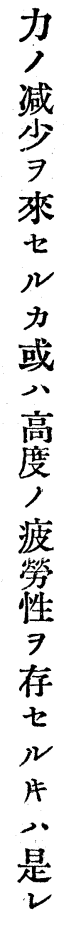 & 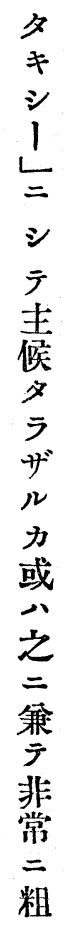 & 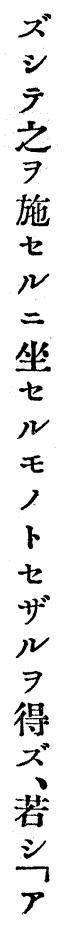 & 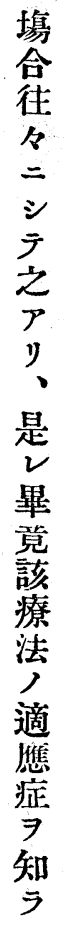 & 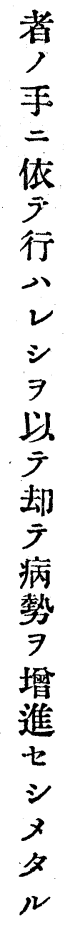 & 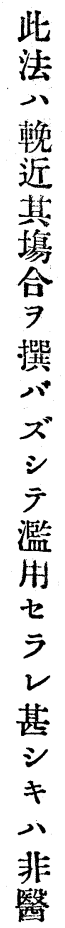 & 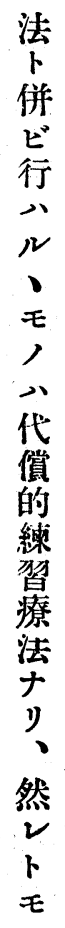 & 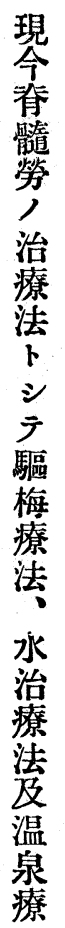 & $\begin{array}{c}\text { (○) } \\
\text { 脊 } \\
\text { 髓 } \\
\text { 勞 } \\
\text { 療 } \\
\text { 法 } \\
\text { 二 } \\
\text { 就 } \\
\text { テ }\end{array}$ & 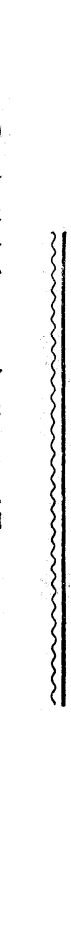 & 够 & I & $\begin{array}{l}\text { 謀 } \\
N \\
\curvearrowright \\
\text { シ } \\
\text { V }\end{array}$ & 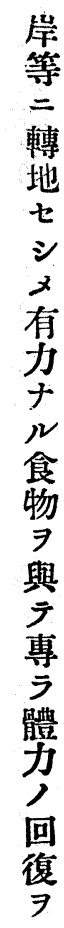 \\
\hline $\begin{array}{l}\text { 洼 } \\
\text { 意 } \\
\text { z } \\
\text { N } \\
= \\
y \\
y\end{array}$ & 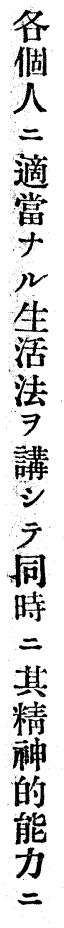 & 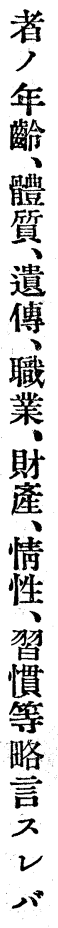 & 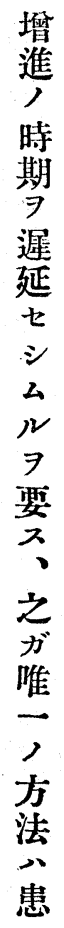 & 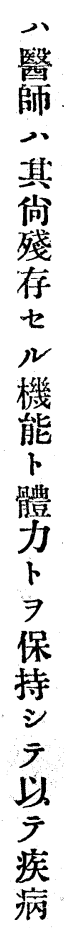 & 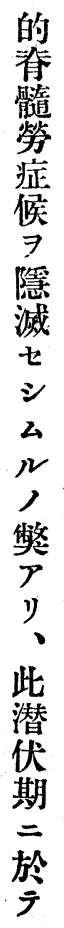 & 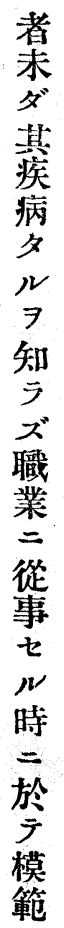 & 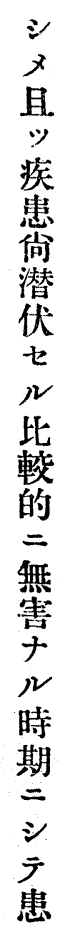 & 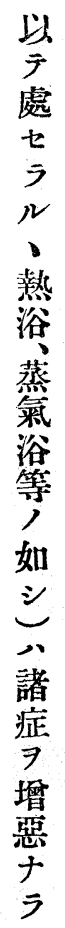 & 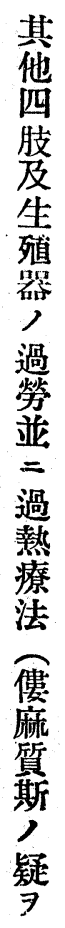 & $\begin{array}{l}\text { 然 } \\
\text { タ } \\
\text { N } \\
\text { 心 } \\
\neq \\
\text { ’ } \\
\text { ミ }\end{array}$ & 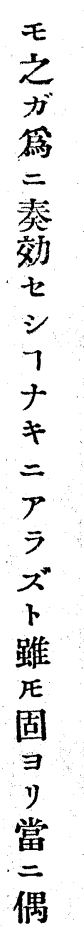 & 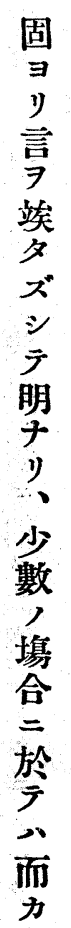 & 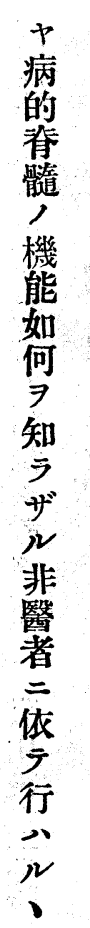 & 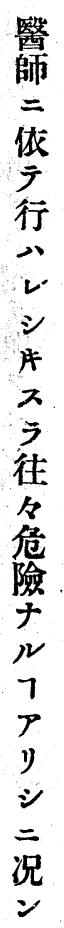 & 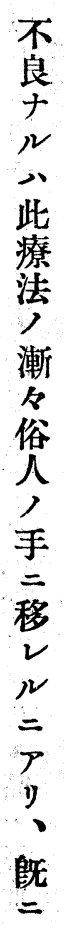 & 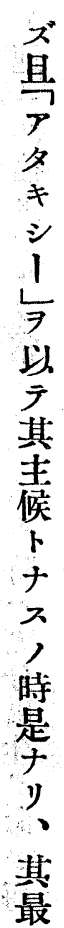 \\
\hline
\end{tabular}

